\title{
Quality of Embryos Produced From Dairy Cows Fed Whole Flaxseed and the Success of Embryo Transfer ${ }^{1}$
}

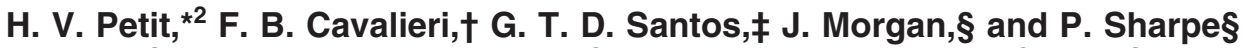 \\ *Dairy and Swine Research and Development Centre, Agriculture and Agri-Food Canada, Stn. Lennoxville, Sherbrooke, \\ Québec, J1M 1Z3, Canada \\ †Departamento de Medicina Veterinaria, Centro Universitario de Maringa, Maringa, PR, Brazil \\ ‡Departamento de Zootecnia, Universidade Estadual de Maringa, Maringa, PR, Brazil \\ §Kemptville Campus, University of Guelph, Kemptville, Ontario, KOG 1JO, Canada
}

\begin{abstract}
The objective of the experiment was to determine the effects of fat supplementation on embryo quality of dairy cows and the subsequent success of embryo transfer into recipient heifers fed the same sources of fat. A total of 30 lactating Holstein cows were allotted on d 18 postpartum to 2 groups of 15 donor cows blocked for similar calving dates. Total mixed diets based on silage and fat supplements were fed for ad libitum intake. On a dry matter basis, diets fed to donor cows contained 7.9\% whole flaxseed or $2.8 \%$ calcium salts of palm oil and those fed to recipient heifers contained $11.4 \%$ whole flaxseed or $4.2 \%$ calcium salts of palm oil. The experiment with donor cows was carried out between d 18 and 109 of lactation. The experimental diets were fed to 121 recipient heifers from wk 8 before estrus synchronization and superovulation to d 50 of gestation. Dietary fat fed to donor cows had no effect on the number of viable embryos per cow $(3.7 \pm 0.5)$, the number of degenerated embryos per cow $(1.8 \pm 0.4)$, or the number of unfertilized oocytes per cow $(2.1 \pm 0.8)$. But feeding flaxseed decreased fertilization rate $(64.3 \mathrm{vs} .78 .4 \%)$ and the percentage of grade 1 to 2 embryos (56.5 vs. $74.1 \%$ ) and increased the embryo degeneration percentage (27.4 vs. $18.2 \%$ ) compared with feeding calcium salts of palm oil. There was no effect of diets fed to donor cows and those fed to recipient heifers for pregnancy rate of heifers. Supplementation with a rich source of n-3 fatty acids decreased quality of embryos from donor lactating dairy cows compared with feeding calcium salts of palm oil, but had no effect on the subsequent pregnancy rate of heifers receiving frozen grade- 1 embryos.
\end{abstract}

Key words: dairy cattle, flaxseed, fatty acid, embryo transfer

\footnotetext{
Received October 16, 2007.

Accepted December 18, 2007.

${ }^{1}$ Contribution number 935 from the Dairy and Swine Research and Development Centre.

${ }^{2}$ Corresponding author: petith@agr.gc.ca
}

\section{INTRODUCTION}

A high proportion of embryonic losses in establishment of early pregnancy in cattle is coincident with the period of embryonic inhibition of uterine $\mathrm{PGF}_{2 \alpha}$ secretion between d 15 and 17, suggesting that some losses may be occurring because certain embryos are unable to inhibit secretion of $\mathrm{PGF}_{2 \alpha}$. Therefore, strategies to further inhibit secretion of $\mathrm{PGF}_{2 \alpha}$ may result in increased embryonic survival and pregnancy rates. Feeding whole flaxseed, which is rich in polyunsaturated fatty acids (PUFA) of the n-3 family, decreased the secretion of PGF metabolite in cows (Petit et al., 2002) and similar findings were reported for cattle fed fish meal (Mattos et al., 2002), another source of n-3 fatty acids. Reduced levels of $\mathrm{PGF}_{2 \alpha}$ could contribute to improved fertility of cows fed n-3 fatty acids (Ambrose et al., 2006) through reduced luteolysis (Thatcher et al., 1997) and vice versa.

Dietary fatty acids have an important effect on gestation rate after first breeding, with a 50\% rate observed for cows fed a source of $n-6$ fatty acids compared with $87.5 \%$ for those fed a source of $n-3$ fatty acids (Petit et al., 2001). Moreover, other results have shown that cows fed whole flaxseed have no embryo mortality compared with those fed either Megalac (Church and Dwight Co. Inc., Princeton, $\mathrm{NJ}$ ) or micronized soybeans (Petit and Twagiramungu, 2006). These results suggest that flaxseed-based diets affect the secretion of prostaglandins and the functional properties of isolated mononuclear cells response, which contribute to improve gestation. Greater proportions of PUFA in phospholipids of oocytes were linked to increased fertility in dairy cows (Zeron et al., 2001), whereas feeding PUFA compared with monounsaturated fatty acids resulted in similar oocyte quality and subsequent in vitro embryo development (Bilby et al., 2006).

There is little information on the effects of dietary fatty acids on the quality of embryos and the success of embryo transfer in dairy cows. It is unknown if fatty acids are more important for the animal supplying the embryo or for the one implanted with the embryo. The 
Table 1. Ingredient and chemical composition of the experimental diets fed to donor cows ${ }^{1}$

\begin{tabular}{lcc}
\hline Item & FLAX & MEG \\
\hline Ingredient, \% of DM & & \\
Alfalfa haylage & 31.5 & 39.4 \\
Corn silage & 30.3 & 36.1 \\
High moisture corn & 19.3 & 9.1 \\
Whole flaxseed $^{2}$ & 7.9 & 0 \\
Grain mix $^{3}$ & 11.0 & 12.6 \\
Megalac $^{4}$ & 0 & 2.8 \\
Chemical analysis & 44.1 & 40.2 \\
DM, \% & 18.0 & 18.0 \\
CP, \% of DM & 6.0 & 6.0 \\
Ether extract, \% of DM & 29.3 & 30.2 \\
NDF, \% of DM & 18.0 & 19.4 \\
ADF, \% of DM & 1.76 & 1.76 \\
NE, Mcal/kg of DM &
\end{tabular}

${ }^{1} \mathrm{FLAX}=$ supplement with whole flaxseed; $\mathrm{MEG}=$ supplement with Megalac (Church and Dwight Inc., Princeton, NJ).

${ }^{2}$ Contained 5.2\% C16:0, 3.4\% C18:0, 18.5\% C18:1, 16.1\% C18:2, and $56.8 \% \mathrm{C} 18: 3$ (\% of total fatty acids).

${ }^{3}$ Contained $52.6 \% \mathrm{CP}, 8.5 \% \mathrm{ADF}$, and $13.5 \% \mathrm{NDF}$.

${ }^{4}$ Contained $6.2 \%$ C14:0, 47.1\% C16:0, 3.5\% C18:0, 32.3\% C18:1, and $7.8 \% \mathrm{C} 18: 2$ (\% of total fatty acids).

hypothesis was that donor cows fed flaxseed, which is a source rich in C18:3, would produce embryos of better quality, thus improving the maintenance of gestation in recipient heifers fed the same fat sources after the transfer of frozen embryos. Therefore, the objectives were to determine the importance of the source of fatty acids fed to donor cows and recipient heifers on the success of embryo transfer. Quality of embryos was determined.

\section{MATERIALS AND METHODS}

\section{Diets}

The experiment was conducted at the University of Guelph Kemptville Campus (Kemptville, Ontario) from June 2001, to July 2002, using 30 multiparous lactating donor cows and 121 recipient Holstein heifers. There were 2 TMR (Table 1) that consisted of fat supplements based on either whole flaxseed (FLAX) or calcium salts of palm fatty acids [Megalac (MEG), Church and Dwight Co. Inc.]. For the donor cows, the 2 treatments were designed at the beginning of the experiment to yield similar $\mathrm{CP}(18 \%)$, ether extract $(6 \%)$, and $\mathrm{NE}_{\mathrm{L}}(1.76$ $\mathrm{Mcal} / \mathrm{kg}$ of $\mathrm{DM}$ ) concentrations and were formulated to meet requirements for cows that were $650 \mathrm{~kg}$ of BW and producing $45 \mathrm{~kg} / \mathrm{d}$ of milk with $3.7 \%$ fat (NRC, 2001). For the recipient heifers, the 2 treatments were designed at the beginning of the experiment to yield similar concentrations of $\mathrm{CP}(15 \%)$, ether extract $(6 \%)$, and $\mathrm{NE}_{\mathrm{G}}$ (1.1 Mcal/kg of DM) and were formulated to meet requirements for growing heifers that were $363 \mathrm{~kg}$ of BW and gained $0.7 \mathrm{~kg} / \mathrm{d}$ (NRC, 2001). Diets were fed twice daily for ad libitum intake. Animals were cared for according to the guidelines of the Canadian Council on Animal Care (CCAC, 1993).

\section{Donor Cows}

Thirty donor cows were blocked on the basis of similar age and calving date and cows within blocks were assigned randomly to 1 of the 2 treatments on d 18 after calving. Cows were housed in tie stalls and fed individually. The experimental rations were introduced on $\mathrm{d} 18$ of lactation over a 3 -d period. After $80 \mathrm{~d}$ of feeding the 2 treatments, a controlled internal drug release device (CIDR, $1.9 \mathrm{~g}$ of progesterone, InterAg, Hamilton, New Zealand) was inserted into the vagina followed $24 \mathrm{~h}$ later by an i.m. injection of $3 \mathrm{mg}$ of estradiol $17 \beta(1.5 \mathrm{mg} /$ $\mathrm{mL}$, Denis Giroux Pharmacy, St. Hyacinthe, Quebec, Canada). Four days after the estradiol injection, cows were superovulated to increase the number of normal fertile eggs per donor. The protocol used decreasing doses of $65,50,40$, and $30 \mathrm{mg}$ twice daily $(0700$ and $1900 \mathrm{~h})$ of FSH $(20 \mathrm{mg} / \mathrm{mL}$, Follitropin V, Bioniche, Belleville, Ontario, Canada) over a 4-d period with injection of $\mathrm{PGF}_{2 \alpha}$ (Estrumate, $500 \mu \mathrm{g}$ of closprostenol, Schering Canada, Pointe-Claire, Quebec, Canada) at the time of the seventh and eighth injections of FSH. The CIDR was removed at the last FSH injection and cows were inseminated 12, 24, and $36 \mathrm{~h}$ later with frozen-thawed Holstein bull semen (Eastern Breeders Inc., Kemptville, Ontario, Canada). Semen came from 2 bulls, ensuring that equal numbers of cows from each treatment group were bred to each bull. On d 6 after AI, embryos were recovered using a standard nonsurgical uterine flushing technique (Elsden et al., 1976) with sterile Dulbecco's PBS and 0.4\% BSA (Fraction V, Sigma, St. Louis, MO). Some cows ( $n=6$ and 7 for FLAX and MEG, respectively) were submitted twice to the superovulation and flushing protocols because of the lower than expected recovery rate of embryos at first flush. Embryos were evaluated for fertilization, and embryo quality was graded ( $1=$ excellent, $2=$ good, $3=$ fair, $4=$ poor, and $5=$ degenerate $)$ as described previously (Ahmad et al., 1995). Only embryos classified as grade 1 were selected for freezing and embryo transfer.

Embryos were frozen as described by Mucci et al. (2006). Briefly, embryos were placed in a holding medium (Vigro Holding Plus, AB Technology, Pullman, WA) for a 10-min equilibration period, loaded into 0.25 $\mathrm{mL}$ plastic straws, and directly placed into a $-7^{\circ} \mathrm{C}$ methanol bath chamber. After $10 \mathrm{~min}$, the straws were seeded, cooled from -7 to $-35^{\circ} \mathrm{C}\left(0.6^{\circ} \mathrm{C} / \mathrm{min}\right)$, and plunged into liquid nitrogen. Still, not all grade 1 embryos were transferred because only a total of 121 recipient heifers were available for the experiment. 
Table 2. Ingredient and chemical composition of the experimental diets fed to recipient heifers ${ }^{1}$

\begin{tabular}{lcc}
\hline Item & FLAX & MEG \\
\hline Ingredient, \% of DM & & \\
Alfalfa haylage & 52.1 & 82.1 \\
Corn silage $^{2}$ & 35.4 & 12.6 \\
Whole flaxseed $^{2}$ & 11.4 & 0 \\
Megalac $^{3}$ & 0 & 4.2 \\
Mineral & 1.1 & 1.1 \\
Chemical analysis & 45.8 & 49.6 \\
DM, \% & 15.0 & 15.2 \\
CP, \% of DM & 6.0 & 6.0 \\
Ether extract, \% of DM & 42.7 & 45.9 \\
NDF, \% of DM & 26.7 & 29.6 \\
ADF, \% of DM & 1.09 & 1.12 \\
Net energy for gain, Mcal/kg of DM & \\
\hline
\end{tabular}

${ }^{1}$ FLAX = supplement with whole flaxseed MEG = supplement with Megalac (Church and Dwight Inc., Princeton, NJ).

${ }^{2}$ Contained $5.2 \%$ C16:0, 3.4\% C18:0, 18.5\% C18:1, $16.1 \%$ C18:2, and $56.8 \% \mathrm{C} 18: 3$ (\% of total fatty acids).

${ }^{3}$ Contained 6.2\% C14:0, 47.1\% C16:0, 3.5\% C18:0, 32.3\% C18:1, and $7.8 \% \mathrm{C} 18: 2$ ( $\%$ of total fatty acids).

Ovaries of the first 5 blocks of donor cows ( $\mathrm{n}=5$ for both FLAX and MEG) were examined by real-time ultrasonography (Aloka SSD-500, Aloka Co. Ltd., Tokyo, Japan) with a $5-\mathrm{MHz}$ linear-array transrectal transducer twice weekly (Monday p.m. and Friday a.m.) from the first day of the experiment ( $\mathrm{d} 18$ of lactation) until initiation of the estrus synchronization protocol (d 98 of lactation).

\section{Recipient Heifers}

A total of 121 normally cyclic Holstein heifers with a range of age from 14 to 26 mo were blocked on the basis of age, and heifers within blocks were assigned randomly to 1 of the 2 TMR (FLAX and MEG). Heifers averaged $360 \mathrm{~kg}$ of BW (SEM = 4.8) at 12 mo of age. Plasma progesterone concentrations were measured twice weekly for 2 wk at 10 and 12 mo of age; when progesterone was $\geq 1.0 \mathrm{ng} / \mathrm{mL}$ it was categorized as high and deemed indicative of luteal function. The heifers were pen-fed for ad libitum intake from wk 8 before estrus synchronization and up to $d 50$ of gestation. The diets (Table 2) were introduced gradually over a 3 -d period and met the requirements of growing heifers (NRC, 2001). Diets were fed for $56 \mathrm{~d}$ to heifers before inducing estrus synchronization ( 2 i.m. injections of $2 \mathrm{~mL}$ of Estrumate $12 \mathrm{~d}$ apart, $500 \mu \mathrm{g}$ of cloprostenol, Schering Canada). Detection of estrus was done 3 times daily from $d$ 56 to 68 . Seven days after being observed in estrus, an embryo selected at random from either a FLAX or MEG donor cow was transferred directly into the uterus of the recipient to have one-fourth of the heifers fed MEG receiving an embryo from a cow fed MEG, one-fourth of
Table 3. Quality of embryos collected on d 7 following AI in donor Holstein cows fed a concentrate containing $7.9 \%$ whole flaxseed (FLAX) or $2.8 \%$ calcium salts of palm oil (MEG)

\begin{tabular}{|c|c|c|c|}
\hline Item & FLAX & MEG & SEM \\
\hline Cows per treatment & 13 & 13 & \\
\hline Recovery per cow ${ }^{1} \mathrm{n}$ & 7.9 & 7.3 & 1.1 \\
\hline Viable embryos per cow, $\mathrm{n}$ & 3.1 & 4.3 & 0.5 \\
\hline Degenerated embryos per cow, $\mathrm{n}$ & 2.3 & 1.3 & 0.4 \\
\hline Unfertilized oocytes per cow, n & 2.5 & 1.7 & 0.8 \\
\hline Total recovery, ${ }^{1} \mathrm{n}$ & 168 & 148 & \\
\hline Total flushings, $\mathrm{n}$ & 19 & 20 & \\
\hline Fertilization rate, $\%$ & $64.3^{\mathrm{b}}$ & $78.4^{\mathrm{a}}$ & \\
\hline$(\mathrm{n}=\text { embryos } / \mathrm{n}=\text { total recovery })^{2}$ & $108 / 168$ & $116 / 148$ & \\
\hline Embryo degeneration, \% & $27.4^{\mathrm{a}}$ & $18.2^{\mathrm{b}}$ & \\
\hline$(\mathrm{n}=$ grade 5 embryos $/ \mathrm{n}=$ total recovery $)$ & $46 / 168$ & $27 / 148$ & \\
\hline Grade 1 to 2 embryos, $\%$ & $56.5^{\mathrm{b}}$ & $74.1^{\mathrm{a}}$ & \\
\hline$(\mathrm{n} / \mathrm{n} \text { embryos })^{3}$ & $61 / 108$ & $86 / 116$ & \\
\hline Grade 3 to 4 embryos, $\%$ & 0.9 & 2.6 & \\
\hline$(\mathrm{n} / \mathrm{n} \text { embryos })^{3}$ & $1 / 108$ & $3 / 116$ & \\
\hline
\end{tabular}

${ }^{\mathrm{a}, \mathrm{b}}$ Means within rows with different superscripts differ $(P<0.05)$

${ }^{1}$ Embryos + unfertilized oocytes.

${ }^{2}$ Total number embryos + unfertilized oocytes recovered.

${ }^{3}$ Total number of embryos recovered.

the heifers fed MEG receiving an embryo from a cow fed FLAX, one-fourth of the heifers fed FLAX receiving an embryo from a cow fed MEG, and one-fourth of the heifers fed FLAX receiving an embryo from a cow fed FLAX. Pregnancy diagnosis was performed on d 50 from estrus using real time ultrasound. Pregnancy rate was defined as the proportion of heifers that were detected in estrus and inseminated that were pregnant on $\mathrm{d} 50$.

\section{Statistical Analysis}

All results were subjected to ANOVA using the GLM procedure of SAS (SAS Institute, 2000). Data on the quality of embryos were analyzed as a randomized block design and treatment was the main source of variation in the model. The number and percentage of recipient heifers pregnant was tested using a chi-square test. Probability values $>0.05$ were considered nonsignificant.

\section{RESULTS AND DISCUSSION}

The results presented on quality of embryos are based on data from 13 cows per diet from the original number of cows assigned to the trial because no embryos were collected from 2 cows per diet. The number of total embryo and unfertilized ova averaged 7.9 and 7.3 for cows fed FLAX and MEG, respectively, and there was no difference $(P>0.05)$ between diets (Table 3). Moreover, the source of fat fed to donor cows had no effect $(P>0.05)$ on the number of viable embryos per cow, the number of degenerated embryos per cow, or the number of unfertilized oocytes per cow. The numbers of viable embryos collected from cows fed MEG was within the range of 
3.4 to 7.1 reported between 1980 and 2005 for 4 different embryo transfer programs in North America (Hasler, 2006).

Feeding FLAX compared with MEG resulted in a lower $(P<0.05)$ fertilization rate (Table 3$)$. Nevertheless, fertilization rates of cows fed FLAX and MEG were within the range of 55.3 to $87.8 \%$, respectively, reported during summer and winter for lactating cows (Sartori et al., 2002). Feeding sources of supplemental fat enriched in C18:2 and C18:3 increased follicle and corpus luteum sizes in lactating dairy cows during the summer compared with feeding supplemental fat enriched in C18:1, but there was no difference in oocyte quality among fat sources as determined by the subsequent capacity to form a developing embryo after in vitro fertilization (Bilby et al., 2006). In vitro bovine embryos have greater concentrations of fatty acids than in vivo embryos (Shamsuddin and Rodriguez-Martinez, 1994), which might alleviate the effect of dietary fatty acids on oocyte quality and subsequent fertilization rate.

Embryo degeneration was significantly greater $(P<$ 0.05 ) for cows supplemented with FLAX compared with those supplemented with MEG (Table 3), which may result from a difference in embryo quality when feeding different sources of fatty acids. Moreover, the percentage of grade 1 to 2 embryos was significantly lower $(P<0.05)$ for cows fed FLAX compared with those fed MEG (Table 3 ), although both percentages were greater than those of grade 1 to 3 embryos reported for lactating cows during summer (52.8\%) and winter (33.3\%; Sartori et al., 2002). Flaxseed contains about $55 \%$ of total fatty acids as linolenic acid (Ambrose et al., 2006), which could compromise embryo development and increase degeneration of embryos from cows fed flaxseed. Inhibition of embryo development was correlated with the number of double bonds in fatty acids (Nonogaki et al., 1994), and FLAX contains greater concentrations of long-chain fatty acids than MEG (Table 1).

The mechanisms producing lower embryo quality in cows fed FLAX compared with those fed MEG could be manifold. Dominant follicle size was increased in cows fed diets enriched in PUFA compared with cows fed a diet enriched in monounsaturated fatty acids (Bilby et al., 2006). Larger ovulating dominant follicles in heifers resulted in larger corpora lutea (Sartori et al., 2002), and larger corpora lutea were detected in lactating dairy cows that received high amounts of $n-3$ fatty acids through the diet as formaldehyde-treated flaxseed or as a mixture of formaldehyde-treated flaxseed and fish oil (Petit and Twagiramungu, 2006). In some cases, feeding calcium salts of fatty acids delayed or prevented follicle turnover and resulted in the dominant follicle becoming older and larger (Moallem et al., 1999), which could contribute to decreased quality of embryos as reported in
Table 4. Pregnancy rate of recipient heifers fed either $11.4 \%$ whole flaxseed (FLAX) or $4.2 \%$ calcium salts of palm oil (MEG) and receiving embryos from cows fed either FLAX or MEG

\begin{tabular}{lllcl}
\hline Item & $\begin{array}{c}\text { FLAX- } \\
\text { FLAX }\end{array}$ & $\begin{array}{l}\text { MEG- } \\
\text { FLAX }\end{array}$ & $\begin{array}{c}\text { FLAX- } \\
\text { MEG }\end{array}$ & $\begin{array}{l}\text { MEG- } \\
\text { MEG }\end{array}$ \\
\hline Heifers per treatment, $\mathrm{n}$ & 33 & 26 & 28 & 34 \\
Pregnancy rate, $\%$ & 39.4 & 42.3 & 28.6 & 44.1 \\
Pregnancy rate, $\mathrm{n} / \mathrm{n}$ & $13 / 33$ & $11 / 26$ & $8 / 28$ & $15 / 34$ \\
\hline
\end{tabular}

the present experiment for cows fed FLAX as a result of overmaturation of oocytes.

The number of transferable embryos tended to increase as the dietary energy intake decreased (Nolan et al., 1998). Yet, similar DMI for cows fed whole flaxseed and those fed calcium salts of palm oil but lower digestibility on the flaxseed-based diet (Petit, 2002) may have resulted in lower intake of energy for cows fed FLAX, thus contributing to decrease the number of grade 1 to 2 embryos for cows fed FLAX compared with those fed MEG.

Progesterone concentrations were $\geq 1.0 \mathrm{ng} / \mathrm{mL}$ for 35 and $67 \%$ of the heifers at 10 and 12 mo of age, respectively, which indicated luteal function. There was no interaction $(P>0.05)$ between diets fed to donor cows and those fed to recipient heifers for pregnancy rate of heifers. Pregnancy rate of heifers fed FLAX and MEG were similar between treatments and averaged 34.4 and 43.3\%, respectively (Table 4). Embryos collected from cows fed FLAX and MEG resulted, respectively, in an average pregnancy rate of 40.7 and $36.4 \%$ in recipient heifers.

No beneficial effect of feeding flaxseed as a dietary ingredient on pregnancy rate was found in the present experiment, suggesting that factors other than synthesis of $\mathrm{PGF}_{2 \alpha}$ were involved after embryo transfer in recipient heifers. Fish meal supplementation increased pregnancy rate in dairy herds of low fertility, but not in those of high fertility (Burke et al., 1997), and the pregnancy rate of multiparous cows was lower than that of nulliparous heifers after embryo transfer (Hasler, 2006), suggesting that the effects of feeding n-3 fatty acids on pregnancy rate were more beneficial in multiparous than primiparous cows such as those used in the present experiment.

The lack of any difference in pregnancy rate between cows fed MEG and those fed FLAX would suggest that dietary fatty acids fed at the same concentration of fat in the DM had no effect on the integrity of embryos following freezing, which might result from similar fat concentrations in embryos. Discrepancies between experiments could be due to both diets being supplemented with fat and because embryos were flushed from cows in the present study, whereas other experiments compared a fat-supplemented diet to a no-fat diet (Zeron et 
al., 2002) and used embryos obtained by in vitro fertilization (Hochi et al., 1999; Bilby et al., 2006; Pereira et al., 2007).

In conclusion, the hypothesis that feeding a source of linolenic acid in the form of flaxseed to recipient heifers would improve the maintenance of gestation after embryo transfer because of better quality of frozen embryos was not supported by the present experiment. Feeding a rich source of $n-3$ fatty acids compared with calcium salts of palm fatty acids decreased the quality of embryos from donor lactating dairy cows, as shown by the lower fertilization rate and higher embryo degeneration, but there was no effect on the subsequent pregnancy rate of heifers receiving frozen grade 1 embryos. Feeding n-3 fatty acids did not seem to modify the uterine environment of recipient heifers as shown by the lack of any dietary effect on the percentage of pregnancy following the transfer of embryos. This suggests that the previously documented benefits of $n-3$ fatty acids on the fertility of dairy cows reflect actions at alternative biological windows.

\section{ACKNOWLEDGMENTS}

The authors thank Blair Dow, Albert Koekkoek, Jahnnis Pitty Del Cid, Luc Besner, and Jim Vander Meer at Kemptville, and L. Veilleux and I. Sabourin at Sherbrooke for technical assistance. This project was sponsored in part by the Matching Investment Initiative of Agriculture and Agri-Food Canada and the Ontario Ministry of Agriculture and Food and Rural Affairs.

\section{REFERENCES}

Ahmad, N., F. N. Schrick, R. L. Butcher, and E. K. Inskeep. 1995. Effect of persistent follicles on early embryonic losses in beef cows. Biol. Reprod. 52:1129-1135.

Ambrose, D. J., J. P. Kastelic, R. Corbett, P. A. Pitney, H. V. Petit, J. A. Small, and P. Zalkovic. 2006. Lower pregnancy losses in lactating dairy cows fed a diet enriched in alpha-linolenic acid. J. Dairy Sci. 89:3066-3074.

Bilby, T. R., J. Block, B. C. do Amaral, O. Sa Filho, F. T. Silvestre, P. J. Hanser, C. R. Staples, and W. W. Thatcher. 2006. Effects of dietary unsaturated fatty acids on oocyte quality and follicular development in lactating dairy cows in summer. J. Dairy Sci. 89:3891-3903.

Burke, J. M., C. R. Staples, C. A. Risco, R. L. De la Sota, and W. W. Thatcher. 1997. Effect of ruminant grade menhaden fish meal on reproductive and productive performance of lactating dairy cows. J. Dairy Sci. 80:3386-3398.

CCAC. 1993. Guide to Care and Use of Experimental Animals. Vol. 1. E. D. Offert, B. M. Cross and A. A. McWilliam, ed. CCAC, Ottawa, Ontario, Canada.

Elsden, R. P., J. F. Hasler, and G. E. Seidel Jr. 1976. Nonsurgical recovery of bovine eggs. Theriogenology 6:523-532.
Hasler, J. F. 2006. The Holstein cow in embryo transfer today as compared to 20 years ago. Theriogenology 65:4-16.

Hochi, S., K. Kimura, and K. Hanada. 1999. Effect of linoleic acidalbumin in the culture medium on freezing sensitivity of in vitroproduced bovine morulae. Theriogenology 52:497-504.

Mattos, R., C. R. Staples, J. Williams, A. Amorocho, M. A. McGuire, and W. W. Thatcher. 2002. Uterine, ovarian, and production responses of lactating dairy cows to increasing dietary concentrations of menhaden fish meal. J. Dairy Sci. 85:755-764.

Moallem, U., Y. Folman, A. Bor, A. Arav, and D. Sklan. 1999. Effect of calcium soaps of fatty acids and administration of somatotropin on milk production, preovulatory follicular development, and plasma and follicular fluid lipid composition in high yielding dairy cows. J. Dairy Sci. 82:2358-2368.

Mucci, N., J. Aller, G. G. Kaiser, F. Hozbor, J. Cabodevila, and R. H. Alberio. 2006. Effect of estrous cow serum during bovine embryo culture on blastocyst development and cryotolerance after slow freezing or vitrification. Theriogenology 65:1551-1562.

Nolan, R., D. O'Callaghan, R. T. Duby, P. Lonergan, and M. P. Boland. 1998. The influence of short-term nutrient changes on follicle growth and embryo production following superovulation in beef heifers. Theriogenology 50:1263-1274.

Nonogaki, T., Y. Noda, Y. Goto, J. Kishi, and T. Mori. 1994. Developmental blockage of mouse embryos caused by fatty acids. J. Assist. Reprod. Genet. 11:482-488.

NRC. 2001. Nutrient Requirements of Beef Cattle. 7th rev. ed. Nat. Acad. Press, Washington, DC.

Pereira, R. M., M. C. Baptista, M. I. Vasques, A. E. M. Horta, P. V. Portugal, R. J. B. Bessa, J. Chagas e Silva, M. Silva Pereira, and C. C. Marques. 2007. Cryosurvival of bovine blastocysts is enhanced by culture with trans-10 cis-12 conjugated linoleic acid (10t,12c CLA). Anim. Reprod. Sci. 98:293-301.

Petit, H. V. 2002. Digestion, milk production, milk composition, and blood composition of dairy cows fed whole flaxseed. J. Dairy Sci. 85:1482-1490.

Petit, H. V., R. J. Dewhurst, J. G. Proulx, M. Khalid, W. Haresign, and $\mathrm{H}$. Twagiramungu. 2001. Milk production, milk composition, and reproductive function of dairy cows fed different fats. Can. J. Anim. Sci. 81:263-271.

Petit, H. V., R. J. Dewhurst, N. D. Scollan, J. G. Proulx, M. Khalid, W. Haresign, H. Twagiramungu, and G. E. Mann. 2002. Milk production and composition, ovarian function, and prostaglandin secretion of dairy cows fed omega-3 fats. J. Dairy Sci. 85:889-899.

Petit, H. V., and H. Twagiramungu. 2006. Conception rate and reproductive function of dairy cows fed different fat sources. Theriogenology 66:1316-1324.

Sartori, R., R. Sartor-Bergfelt, S. A. Mertens, J. N. Guenther, J. J. Parrish, and M. C. Wiltbank. 2002. Fertilization and early embryonic development in heifers and lactating cows in summer and lactating and dry cows in winter. J. Dairy Sci. 85:2803-2812.

SAS Institute. 2000. SAS/STAT User's Guide. Release 8.02. SAS Institute Inc., Cary NC.

Shamsuddin, M., and H. Rodriguez-Martinez. 1994. Fine structure of bovine blastocysts developed either in serum-free medium or in conventional co-culture with oviduct epithelial cells. J. Vet. Med. A 41:307-316.

Thatcher, W. W., M. Binelli, J. Burke, C. R. Staples, J. D. Ambrose, and S. Coelho. 1997. Antiluteolytic signals between the conceptus and endometrium. Theriogenology 47:131-140.

Zeron, Y., A. Ocheretny, O. Kedar, A. Borochov, D. Sklan, and A. Arav. 2001. Seasonal changes in bovine fertility: Relation to developmental competence of oocytes, membrane properties and fatty acid composition of follicles. Reproduction 121:447-454.

Zeron, Y., A. Sklan, and A. Arav. 2002. Effect of polyunsaturated fatty acid supplementation on biophysical parameters and chilling sensitivity of ewe oocytes. Mol. Reprod. Dev. 61:271-278. 